\title{
Development and Comparison of Cross-Linking and Non-Crosslinking Probe-Gold Nanoparticle Hybridization Assays for Direct Detection of Unamplified Bovine Viral Diarrhea Virus-RNA
}

\section{Zahra Heidari}

Shahid Chamran University of Ahvaz

Seyedeh Elham Rezatofighi ( $\nabla$ e.tofighi@yahoo.com )

Shahid Chamran University of Ahvaz https://orcid.org/0000-0003-1373-7346

\section{Saadat Rastegarzadeh}

Shahid Chamran University of Ahvaz

\section{Research article}

Keywords: Bovine viral diarrhea virus, Gold nanoparticles, Cross-linking, Non-crosslinking, Hybridization assay

Posted Date: February 19th, 2021

DOl: https://doi.org/10.21203/rs.3.rs-244758/v1

License: (c) (1) This work is licensed under a Creative Commons Attribution 4.0 International License. Read Full License

Version of Record: A version of this preprint was published at BMC Biotechnology on April 23rd, 2021. See the published version at https://doi.org/10.1186/s12896-021-00691-w. 


\section{Abstract}

Background: Bovine viral diarrhea virus (BVDV) is a major economic disease that has been spread in most countries. In addition to vaccination, one of the main ways to control the disease and prevent it from spreading is to detect and cull infected animals, especially those with persistent infection (PI). We developed and compared two colorimetric biosensor assays based on probe-modified gold nanoparticles (AuNPs) to detect BVDV. Specific probes were designed to detect the $5 \square$ untranslated region of BVDVRNA. The thiolated probes were immobilized on the surface of the AuNPs. Two methods of cross-linking $(\mathrm{CL})$ and non-crosslinking $(\mathrm{NCL})$ probe-AuNPs hybridization were developed and compared.

Results: The hybridization of positive targets with the two probe-AuNPs formed a polymeric network between the AuNPs which led to the aggregation of nanoparticles and color change from red to blue. Alternatively, in the NCL mode, the hybridization of complementary targets with the probe-AuNPs resulted in the increased electrostatic repulsion in nanoparticles and the increased stabilization against saltinduced aggregation. The $\mathrm{CL}$ and $\mathrm{NCL}$ assays had detection limits of 6.83 and $44.36 \mathrm{ng} /$ reaction, respectively.

Conclusion: The CL assay showed a higher sensitivity and specificity; in contrast, the NCL assay did not require optimizing and controlling of hybridization temperature and showed a higher response speed. However, both the developed methods are cost-effective and easy to perform and also could be implemented on-site or in local laboratories in low-resource countries.

\section{Background}

Bovine viral diarrhea virus (BVDV) belongs to the Pestivirus genus, Flaviviridae family. Previously, BVDV was divided into two species of BVDV-1 and BVDV-2 based on genetic and antigenic differences [1]. However, recently, International Committee on Taxonomy of Viruses (ICTV) has reorganized the Pestivirus genus to eleven species, including Pestivirus A-K. Under this new classification, BVDV-1 and BVDV-2 correspond to Pestivirus A and Pestivirus B, respectively. In the current study, we used previous names consistent with previous studies [2]. BVDV has a positive sense, the single-stranded RNA (ssRNA) genome, with an open reading frame (ORF) located between $5^{\prime}$ and $3^{\prime}$ untranslated regions (5'UTR, 3'UTR) [3]. BVDV causes diseases in ruminants, especially cattle [1]. Symptoms of BVDV infection in cattle include fever, diarrhea, abortion, stillbirth, congenital defective calf, decreased milk production, infertility, and even death. Infection of cows with BVDV during early pregnancy (the days 30-120) may lead to the birth of persistently infected (PI) calves. $\mathrm{PI}$ animals are significant because they remain viremic throughout their lives and serve as infection sources in cattle herds [4, 5]. BVDV is highly essential economically, as the mean annual loss directly attributed to BVDV is estimated to be $42.14 €$ per livestock [6]. The virus has spread in most countries, including Iran. Noaman and Nabinejad reported that the prevalence of BVDV in Isfahan Province, Iran, is $52.8 \%$ and $100 \%$ in cattle and farms, respectively [7]. In other provinces, the prevalence is almost the same $[8,9]$. 
One way to control the disease and prevent it from spreading is to detect and cull infected animals, especially PI animals. Several methods have been used for BVDV detection including virus isolation (VI), immunohistochemistry, antigen capture enzyme-linked immunosorbent assay (AC-ELISA), reverse transcriptase polymerase chain reaction (RT-PCR), and real-time RT-PCR $[1,10]$. VI is a "gold standard" diagnostic technique for BVDV (Sandvik, 2005); however, it is a labor-intensive and time-consuming process [10]. AC-ELISA has good sensitivity and specificity for detecting BVDV antigens; but, the presence of BVDV maternal antibodies or protein degradation influences results obtained by ELISA $[1,10]$. Molecular techniques including RT-PCR and real-time RT-PCR have high accuracy; however, these assays are expensive and need specialized equipment and skilled personnel. Unfortunately, none of these assays can be performed in the field or in small local laboratories.

Using colorimetric biosensors for the rapid detection of biomolecules has recently attracted attentions [11]. Gold nanoparticles (AuNPs) are among the widely used nanomaterials in this field. AuNPs due to unique properties including easy synthesis, broad size and shape controllability, functionalization with biomolecules, long-term stability, and optical properties have been extensively applied to construct optical biosensors [11-13]. The surface plasmon resonance (SPR) is led to the solution of AuNPs with diameters of 5-30 nm showing a red color and the an absorption peak of around $520 \mathrm{~nm}$; while, aggregated AuNPs' color changes from red to purple or blue as SPR shifts to longer wavelengths $[14,15]$. This phenomenon helps to design diagnostic tests based on color change in AuNPs, and thus, it is called AuNP-based colorimetric assay [16-18]. The assay has been applied for detecting of some pathogens including influenza virus [19, 20], Klebsiella pneumonia [12], Brucella spp. [21], Salmonella [22], Escherichia coli [23], and Middle East respiratory syndrome coronavirus [24].

AuNPs due to the negative charge of coated citrate anions have electrostatic repulsion and are stable in dispersed state. When salt is added, $\mathrm{Na}^{+}$neutralizes the negative charge of citrate and thus, AuNPs are aggregated. However, the modification of AuNPs with thiolated DNA probes protects nanoparticles (NPs) against salt-induced aggregation due to the formation of a repulsive electric double layer by negative charges of citrate anions and DNA probes [25]. The thiol-linked oligonucleotide modified AuNPs (herein designated as 'probe-AuNPs') have a key application in nucleic acid detection by two platforms of crosslinking (CL) and non-crosslinking (NCL). In the CL method firstly developed by Mirkin et al., two contiguous and complementary probe-AuNPs to the target nucleic acid are used [26]. Through the hybridization of probe-AuNPs with the target sequence, a polymeric network is formed and causes color change in the solution from red to purple or blue; however, the color remains red in the absence of target nucleic acid (Fig. 1) [27, 28]. In latter mode, the assay is based on a non-crosslinking hybridization platform where one type of probe-AuNPs is used. In this assay, the aggregation of NPs is induced by increasing salt concentration. In the presence of the target sequence duo to the hybridization of the target with the probe, NPs are protected from salt-induced aggregation and the solution remains red. However, in the presence of non-complementary or mismatched sequences, the solution's changes from red to blue (Fig. 1) [23, 27, 29]. 
The use of probe-AuNPs for the colorimetric detection of nucleic acid targets represents an alternative to common amplification and non-amplification molecular assays. Herein, we developed and compared two BVDV-RNA detection methods using CL and NCL probe-AuNPs hybridization assays.

\section{Results}

\section{Synthesis and characterization of AuNPs}

Transmission electron microscopy (TEM) images showed that the AuNPs were synthesized and had a mean diameter of $13 \mathrm{~nm}$ (Fig 2.a). Dynamic light scattering (DLS) analysis revealed that more than 95\% of the AuNPs were in the range of 7 to $22 \mathrm{~nm}$ (Fig 2b). The UV-vis absorption spectrum of the free AuNPs exhibited a maximum peak at $520 \mathrm{~nm}$ (Fig $2 \mathrm{c}$ and $2 \mathrm{~d}$ ).

\section{Functionalization of AuNPs}

To modify the AuNPs, different probe to AuNP ratios including 50:1, 100:1, and 200:1 were used. When the probe concentration was low in the solution, the AuNPs were aggregated immediately after adding $\mathrm{NaCl}$. However, the probe to AuNP ratio of 200:1, the probes protected the NPs from aggregation with $\mathrm{NaCl}$. After functionalizing the AuNPs, the SPR peak shifted slightly from $520 \mathrm{~nm}$ to $525 \mathrm{~nm}$ (Fig 2c and $2 \mathrm{~d}$ ). The probe-AuNPs were stable at the high concentration of $\mathrm{NaCl}$ (up to $2 \mathrm{M}$ ). However, the nonfunctionalized AuNPs were aggregated at the low concentration of $\mathrm{NaCl}(0.1 \mathrm{M})$, and the solution's color changed from red to blue. The phosphates of the probe nucleotides increased the negative surface charge of the AuNPs, leading to the repulsion interaction of the AuNPs and the increased stability of the NPs [30].

\section{Optimization of CL and NCL probe-AuNPs hybridization reaction}

To optimize the $\mathrm{CL}$ hybridization reaction, different denaturation temperatures of $80,85,90$, and $95^{\circ} \mathrm{C}$ at times of $1,2,3,4$, and $5 \mathrm{~min}$ and annealing temperatures of 45,50 , and $55^{\circ} \mathrm{C}$ were investigated. According to the best signal-to-noise level, temperatures of $90^{\circ} \mathrm{C}$ for $3 \mathrm{~min}$ and $45^{\circ} \mathrm{C}$ were applied for hybridization and annealing, respectively. The various $\mathrm{NaCl}$ concentrations were analyzed to optimize the annealing of the target to the probes. The optimum concentration of $\mathrm{NaCl}$ in hybridization buffer was found to be $0.3 \mathrm{M}$.

The optimization of NCL reaction was performed at different denaturation temperatures and times such as above, and finally, the temperature of $90^{\circ} \mathrm{C}$ for 3 min was applied.

\section{Analytical sensitivity of CL probe-AuNPs hybridization assay}

To evaluate the sensitivity of the developed methods, various BVDV-RNA concentrations of $12.24 \times 10^{\wedge}$ $(-6)$ to $12.24 \times 10^{\wedge}(6)$ were tested. The color change of the reaction was observed with the naked eye in the $10.24 \mathrm{ng} /$ reaction of RNA. The limit of detection (LOD) was determined as $6.83 \mathrm{ng} /$ reaction. Although the color change was not visually detectable at this RNA concentration, a change was observed in the 
wavelength using a spectrophotometer, indicating the high sensitivity of the newly developed method. The absorbance spectra of all the RNA concentrations were measured, and linear regression was determined. A linear relationship ( $R=0.9977)$ was found between absorbance ratios at $620 \mathrm{~nm} / 525 \mathrm{~nm}$ and various RNA concentrations in the range 1.24 to $12.4 \mathrm{ng} /$ reaction (Fig 3a). By increasing the RNA concentration, the solution's color shifted from red to blue. The sensitivity of the developed method was determined according to plaque forming unite (PFU)/mL. The LOD was estimated to be 1.4 and 0.5 $\mathrm{PFU} /$ reaction, respectively, with the naked eye and a spectrophotometer (Fig $3 b$ ).

The detection limits of RT-nested multiplex-PCR and real-time RT-PCR were obtained to be $12.24 \times 10^{\wedge}(-4)$ and $12.24 \times 10^{\wedge}(-5) \mathrm{ng} /$ reaction, respectively, and thus, they were both more sensitive than the probeAuNPs hybridization assay.

\section{Analytical sensitivity of NCL probe-AuNPs hybridization assay}

The sensitivity of the NCL assay was found 62 and $44.36 \mathrm{ng} /$ reaction of RNA with the naked eye and a spectrophotometer, respectively. The sensitivity of the NCL method according to PFU was calculated 42 and 10.64 PFU/mL using visual and instrument, respectively. Fig 4 shows the linear relationship between the absorption A620/A525 ratio and the increased BVDV-RNA concentration in the range of 15.5 to 62 $\mathrm{ng} /$ reaction $(\mathrm{R} 2 \mathrm{=}$ 0.9901). In contrast to the $\mathrm{CL}$ assay, in the NCL method by increasing the RNA concentration, the solution's color shifted from blue to red.

\section{Analytical specificity of CL and NCL probe-AuNPs hybridization assays}

Different sequences of the $5^{\prime}$ untranslated region (5'UTR) of BVDV-RNA were aligned and a conserved region of the viral genome was selected as the target. Two probes were designed to detect and hybridize with the target sequence. The specificity of the probes was assessed by basic local alignment search tool (BLAST) search, and results showed that the probes were specific for BVDV-1 and BVDV-2.

The new assays were performed on several positive and negative control samples. All the negative controls including unmatched and mismatch DNA sequences, uninfected Madin-Darby bovine kidney (MDBK) and Razi Bovine Kidney (RBK) cell lines, blood samples of healthy bovines, foot-and-mouth disease virus (FMDV), bovine leukemia virus cultivated on fetal lamb kidney (BLV-FLK), bovineherpesvirus 1 (BoHV-1), Mycobacterium bovis, E. coli 0157:H7, and Pasteurella multocida were negative for both the newly developed assays. The reactions' color remained red in the $C L$ assay, while the solutions' color changed from red to blue in the NCL assay. However, for the CL assay, positive controls including references and archival samples changed the reaction's color from red to blue and were considered positive. In the NCL method, in contrast, the color of all the positive samples remained red.

\section{Relative diagnostic sensitivity and specificity}

Fifty clinical samples suspected of infection with BVDV were investigated simultaneously using RTnested multiplex-PCR, real-time RT-PCR, and CL and NCL probe-AuNPs hybridization assays. The relative diagnostic sensitivity and specificity of the $C L$ and NCL developed methods were calculated according to 
the following formula: sensitivity: and specificity: , where TP, FN, TN, and FP are true positive, false negative, true negative, and false positive, respectively. Of the 50 specimens, 20 were detected as BVDV using RT-nested multiplex-PCR and real-time RT-PCR; however, the CL and NCL assays could detect 18 and 17 of the specimens, respectively. Samples unidentified by the new methods were confirmed as BVDV by culturing the samples on cells, and thus, were considered true positive. No samples were detected positive by the CL probe-AuNPs hybridization assay and negative by the other two methods. However, one true negative sample was detected as BVDV in the NCL assay. Based on these results, the relative diagnostic sensitivity and specificity of the newly developed CL method were obtained 90 and $100 \%$, respectively. The overall agreement was $96 \%$ between the molecular tests and the $C L$ assay. The diagnostic sensitivity and specificity of the NCL assay were found 87 and $97 \%$, respectively. An overall agreement of $92 \%$ was found between the molecular tests and the NCL method. The two developed assays had an overall agreement of $96 \%$.

\section{Discussion}

The real-time detection of pathogenic agents has a high interest in various fields including medicine, veterinary science, biosecurity, bioterrorism, and environmental science [31]. The AuNPs colorimetric based assays have the capacity to be automated as chips. By designing and using specific probes, a wide range of pathogenic microorganisms, including bacteria, viruses and fungi can be identified simultaneously [32]. Citrate coated AuNPs prepared by the citrate reduction method are highly favorable for biological assays because of easy synthesis and high yield. Citrate as a capping agent on the surface of AuNPs can be easily replaced by other capping agents such as thiol that help binding of biological compounds to AuNPs [33, 34].

In the current study, we developed two methods of CL and NCL probe-AuNPs hybridization assays to propose novel, fast, sensitive, and enzyme-free methods for the detection of both BVDV-1 and BVDV-2. The first report about using nanomaterials for the detection of viruses was related to 1997, in which AuNPs coupled with silver staining were applied to detect of human papillomavirus $[13,35]$. Since then, NPs, especially AuNPs, have been used to identify viruses in several cases. The basis of these methods is usually the detection of proteins, antigens, or nucleic acid of the virus. Due to the specificity of BVDV-RNA sequence, the proposed methods were designed based on virus nucleic acid detection. The most conserved region of the BVDV-RNA is the 5' UTR sequence, which was detected by both the developed methods. Assessing the specificity of the designed methods showed that this sequence was very suitable for BVDV identification.

Visual and instrument color change detections showed that the CL probe-AuNPs hybridization assay was more sensitive than NCL method. Visual and instrument LOD for CL assay was 10.24 and 6.83 $\mathrm{ng} /$ reaction. Moreover, the LOD for the NCL assay with the naked eye and a spectrophotometer was estimated to be 62 and $44.36 \mathrm{ng} /$ reaction, respectively. However, the both methods exhibited lower sensitivity than RT-nested multiplex PCR and real-time RT-PCR. The reason is that the developed methods are not based on target amplification. The NCL method requires a greater number of target RNA to 
prevent the salt-induced aggregation; therefore, this method is less sensitive than the CL assay. Previously, our research group used unmodified AuNPs assay to detect unamplified BVDV-RNA; however, the two recently developed methods are more sensitive than unmodified AuNPs assay because free probes may be adsorbed to AuNPs and reduce the sensitivity of unmodified AuNPs assay [36]. When peptide nucleic acid (PNA)-probe was used instead of DNA-probe in unmodified AuNPs assay, the assay's sensitivity increased and was almost equivalent to that of the CL assay [37].

The results of analytical specificity showed that the developed $C L$ and NCL assays were selective for the detection of BVDV-RNA. However, the intensity of color difference between positive and negative control samples was greater in the $\mathrm{CL}$ assay than in the NCL method, and thus, detection was easier in the CL assay. The results of relative diagnostic specificity showed that the $C L$ method was more specific than the NCL assay. The probes were designed in a tail-to-tail manner and each probe had a $15 \mathrm{bp}$ specific sequence complemented to adjacent sequences in the target RNA. Therefore, it is feasible to identify a continuous $30 \mathrm{bp}$ region on the genome. This mode action enhances the assay's specificity and decreases the nonspecific binding of probes to the target genome [32]. In the NCL method, only one probe was used and, probably for this reason, specificity was lower in this method than in the CL assay. Compared to RT-nested multiplex-PCR and real-time RT-PCR, the $\mathrm{CL}$ assay had the same specificity but NCL had lower specificity. One of the real negative samples was detected as positive in NCL, which may be due to the nonspecific binding of nucleic acids to the probe-AuNPs. When the salt concentration increases, the negative charge of nucleic acids is neutralized to some extent, causing to increase nonspecific bindings.

The comparison of the developed $\mathrm{CL}$ and NCL assays showed that the both methods were simple, did not need trained personnel or expensive instruments, did not require enzyme or target amplification, and could be read with the naked eye; however, the CL method was more sensitive and specific. The NCL assay required more target RNA than the CL method to identify positive samples. Sato et a/ reported that a single DNA target was sufficient to cross-link two AuNPs together whereas the NCL assay required about 200 target molecules per one AuNP [38]. The advantages of the NCL method included using one type nano-probe, not requiring the optimization and control of hybridization temperature, and having higher reaction speed. Compared to molecular methods investigated in the current study, although the $\mathrm{CL}$ and NCL assays were less sensitive and specific, they were faster and did no need reverse transcription. The developed assays can be directly performed on total RNA and do not require the conversion of RNA to cDNA or amplification.

The design of probes is highly critical in the $\mathrm{CL}$ and NCL assays. The both probes, in addition to having specific complementary sequences to BVDV-RNA, had a 10 base chain of adenine nucleotides at the end, which was connected to AuNP. Poly(A) tails acted as a spacer and reduced the steric hindrance between specific sequences of probes and the AuNP surface, thereby significantly improving the hybridization efficiency $[39,40]$. 
The developed methods cannot detect whether the virus is active or inactive (live or dead). This limitation also exits in other molecular methods, as they can only detect the presence of the virus. The newly developed CL and NCL assays may not be able to find BVDV during the early or end stage of the disease when the virus titer is low. However, these novel methods can effectively identify PI cows or BVDV in the acute phase of the disease and can be performed in the field.

\section{Conclusion}

We developed two methods of CL and NCL colorimetric AuNPs to detect BVDV that were cost-effective, easy to perform, robust, and rapid and also could be performed on-site or in local laboratories in lowresource countries. Comparison of the two developed methods showed that the $\mathrm{CL}$ assay had higher sensitivity and specificity whereas the NCL assay had a higher response speed. These novel methods are beneficial for enhancing BVDV diagnostic efficiency, especially detecting PI animals, effectively controlling the spread of the disease, and reducing losses in cattle farms.

\section{Materials And Methods}

\section{Reference isolates, clinical isolates, and other pathogens}

The reference isolates of NADL-BVDV (BVDV-1) and BVDV-2 (Razi strain) were purchased from the Razi Vaccine and Serum Research Center (Hessarak, Iran) and used as positive controls. The viruses were inoculated to the MDBK cell line in RPMI 1640 fed with 10\% FBS (Gibco, Scotland) and incubated at $37^{\circ} \mathrm{C}$ under $5 \% \mathrm{CO}_{2}$ to form cytopathic effects (CPEs). The titers of the viruses were measured by the PFU assay and calculation of $50 \%$ tissue culture infective dose $\left(\operatorname{TCID}_{50}\right)$ using the Reed and Munech method. The reference strains were used to develop and optimize the hybridization reaction conditions.

Clinical samples were taken of fifty calves with clinical signs of BVDV including diarrhea, fever, respiratory disorders, and still birth. Buffy coats of blood samples were subjected to RNA extraction.

Negative controls included several bacterial and viral bovine pathogens, blood samples of two healthy bovines, and the MDBK cell line. Bacterial pathogens included M. bovis (BCG), E. coli 0157:H7 (ATCC 35218), and P. multocida (ATCC 15742). The used viral pathogens were BLV-FLK, FMDV type 0 IRAN/1/2010, and BoHV-1.

\section{RNA and DNA extraction}

RNA was extracted from buffy coats of the blood samples, reference and archival strains, uninfected MDBK and RBK cell lines, and FMDV using the RNA extraction kit (Bioneer; South Korea) following the manufacturer's instructions.

DNA was extracted from M. bovis, E. coli 0157:H7, P. multocida, BLV-FLK, and BoHV-1 using the DNA extraction kit (Bioneer; South Korea) following the manufacturer's instructions. All the extracted nucleic 
acids were stored at $-80^{\circ} \mathrm{C}$ until used.

\section{RT-nested multiplex-PCR and real-time RT-PCR}

The RNA samples were reversely transcripted to cDNA using the TaKaRa cDNA synthesis kit (Japan) according to the manufacturer's instructions. Nested multiplex-PCR was performed to detect BVDV-1 and BVDV-2 following Gilbert's et al. method [41]. The target location of the primers was the NS5B of BVDVRNA. These primers recognized the fragments of the 369 bp length of BVDV- 1 or the $615 \mathrm{bp}$ of BVDV-2 (Table 1). The real-time RT-PCR was performed using Applied Biosystems (USA) as described by Aebischer et al (Table 1) [42].

\section{Synthesis of AuNPs}

AuNPs were prepared by the citrate reduction of tetrachloroauric acid $\left(\mathrm{HAuCl}_{4}\right)$. Briefly, $50 \mathrm{~mL}$ of $0.01 \%$ $\mathrm{HAuCl}_{4}$ was boiled. Then, $0.6 \mathrm{~mL}$ of $1 \%$ sodium citrate solution was added quickly after boiling stopped and stirring continued. After a few minutes, the solution's color turned from yellow to gray, blue, purple, and finally red. Stirring continued to cool the solution to room temperature.

\section{Characterization of AuNPs}

TEM (Zeiss Em10c, 80 kv, Germany) and DLS with a Malvern instrument (UK) model Nano zs (red badge) ZEN 3600 were used for assessing AuNPs. UV-vis absorption spectra were recorded using UV-visible spectrophotometry (GBC, Cintra 101, Australia).

\section{Design of probes}

The 5'UTR of the BVDV-RNA is the most conserved region of the genome; therefore, this sequence was used to design probes. Thirty BVDV reference sequences (24 BVDV-1 and six BVDV-2 strains) were randomly retrieved from the GenBank database and aligned using ClustalX. The most conserved regions were selected and assessed using the BLAST to select BVDV specific sequences. The length of each probe was considered 15 nucleotides. Complementary sequences at the ends of the probes were avoided. The melting temperatures of the probes were considered within a narrow range. For a better conjugation of the probes to AuNPs, 10 bases of A and the thiol group were added to the connecting end of the probes to AuNPs (Table 1).

\section{Functionalization of AuNPs}

Capping AuNPs with 5'-thiol terminated probe (probe A) and 3'-thiol terminated probe (probe B) was performed using the [18]. For this purpose, $15 \mu \mathrm{L}$ of each probe $(10 \mu \mathrm{M})$ was added separately to $35 \mu \mathrm{L}$ of AuNPs (20 nM). Subsequently, the solutions were incubated at room temperature for 16 hours. The conjugation solutions were then brought to the final concentration of $0.1 \mathrm{M} \mathrm{NaCl}$ and $10 \mathrm{mM}$ phosphate buffer by adding the concentrated solution of $1 \mathrm{M} \mathrm{NaCl} / 100 \mathrm{mM}$ phosphate buffer within 16 hours. Then, the solution was centrifuged three times. After each centrifugation, the supernatant was removed and the 
oily pellet was resuspended in assay buffer ( $10 \mathrm{mM}$ phosphate buffer $/ 0.3 \mathrm{M} \mathrm{NaCl})$. The final concentration of the functionalized AuNPs was considered $10 \mathrm{nM}$. This method was used for the two designed probes. The two probes ( $A$ and $B$ ) were used in the $C L$ assay; while, one of them (probe $A$ or $B$ ) was used in the NCL assay.

\section{Hybridization reaction of CL probe-AuNPs colorimetric assay}

The hybridization of probe-AuNPs and the target was performed by adding $10 \mu \mathrm{L}$ of probe-AuNP (the final concentration of each probe was approximately $0.8 \mu \mathrm{M}$ ) to $5 \mu \mathrm{L}$ of the target. The mixture was denatured at $95^{\circ} \mathrm{C}$ for $3 \mathrm{~min}$ and hybridized at $45^{\circ} \mathrm{C}$ for $10 \mathrm{~min}$. Color changes were assessed with the naked eye and a UV-visible spectrophotometer.

\section{Hybridization reaction of NCL probe-AuNPs colorimetric assay}

The NCL reaction mixture of $20 \mu \mathrm{L}$ volume contained $5 \mu \mathrm{L}$ of target, $4 \mu \mathrm{L}$ of phosphate buffer $(100 \mathrm{mM})$, $10 \mu \mathrm{L}$ of probe-AuNPs (A or B), and water. The mixture was heated at $95^{\circ} \mathrm{C}$ for $3 \mathrm{~min}$; then, incubated at room temperature for $30 \mathrm{~min}$. Finally, $20 \mu \mathrm{L}$ of $\mathrm{NaCl}(4 \mathrm{M})$ was added to the reaction. Color changes was assessed by naked eye and UV-visible spectrophotometer.

\section{Analytical sensitivity and specificity of CL and NCL probe-AuNPs hybridization assays}

The sensitivity of the developed methods was assayed by calculating limit of detection (LOD) according to the following formula: $L O D=3$ standard deviation of the blank. Therefore, ten-fold serial dilutions of RNA extracted from the supernatant of BVDV-infected cells ( 0.012 to $124 \mathrm{ng} /$ reaction) were prepared and analyzed using CL and NCL probe-AuNPs hybridization assays. Moreover, the sensitivity of the new methods was analyzed according to ten-fold serial dilutions of the virus ( 0.014 to $140 \mathrm{PFU} /$ reaction). The results were compared to the sensitivity of RT-nested multiplex-PCR and real-time RT-PCR.

To determine the reaction specificity, several viral and bacterial bovine pathogens (indicated above), bloods of healthy bovines, two different cell lines, and reference and archival strains were assayed by CL and NCL probe-AuNPs hybridization reactions.

\section{Relative diagnostic sensitivity and specificity}

A total of 50 suspected clinical samples were analyzed in parallel using the developed methods, RTnested multiplex-PCR, and real-time RT-PCR as descripted above.

\section{Abbreviations}

Bovine viral diarrhea virus (BVDV); Persistent infection (PI); Gold nanoparticles (AuNPs); Cross-linking (CL); Non-crosslinking (NCL); International Committee on Taxonomy of Viruses (ICTV); Single-stranded RNA (ssRNA); Open reading frame (ORF); 5' and 3' untranslated regions (5'UTR, 3'UTR); Virus isolation $(\mathrm{VI})$, Antigen capture enzyme-linked immunosorbent assay (AC-ELISA), Reverse transcriptase polymerase 
chain reaction (RT-PCR); Surface plasmon resonance (SPR); Nanoparticles (NPs); Madin-Darby bovine kidney (MDBK) Cytopathic effects (CPEs); Plaque forming unit (PFU); 50\% tissue culture infective dose $\left(\mathrm{TCID}_{50}\right)$; Razi Bovine Kidney (RBK); Basic local alignment search tool (BLAST); Transmission Electron Microscopy (TEM); Dynamic light scattering (DLS); Tetrachloroauric acid $\left(\mathrm{HAuCl}_{4}\right)$; Fetal lamb kidney (BLV-FLK), Foot-and-mouth disease virus (FMDV); Bovine-herpesvirus 1 (BoHV-1).

\section{Declarations}

\section{Ethics approval and consent to participate}

Not applicable.

\section{Consent for publication}

Not applicable.

\section{Availability of data and materials}

The datasets used and/or analyzed during the current study are available from the corresponding author on reasonable request.

\section{Competing interests}

The authors declare that they have no competing interests.

\section{Funding}

No funding.

\section{Authors' contributions}

All authors contributed to the design of the experiment. SER designed and supervised the research study. ZH carried out the experiments. SR participated in the design of the study and data analysis. All authors read and approved the final manuscript.

\section{Acknowledgements}

The authors are very thankful to Shahid Chamran University of Ahvaz for the facilities to accomplish the present research project. This study is related to MSc thesis of Zahra Heidari.

\section{References}

1. Spetter MJ, Louge Uriarte EL, Armendano JI, Morrell EL, Cantón GJ, Verna AE, et al. Detection methods and characterization of bovine viral diarrhea virus in aborted fetuses and neonatal calves over a 22-year period. Brazilian journal of microbiology. 2020;51:2077-86. 
2. Walz PH, Chamorro MF, Passler SMF, van der Meer T, A F. RW. Bovine viral diarrhea virus: An updated American College of Veterinary Internal Medicine consensus statement with focus on virus biology, hosts, immunosuppression, and vaccination. J Vet Intern Med. 2020;34:1690-706.

3. Liang H, Geng J, Bai S, Aimuguri A, Gong Z, Feng R, et al. TaqMan real-time PCR for detecting bovine viral diarrhea virus. Pol J Vet Sci. 2019;22:405-13.

4. Kaveh A, Merat E, Samani S, Danandeh S, Soltan Nezhad S. Infectious Causes of Bovine Abortion in Qazvin Province, Iran. Arch Razi Inst. 2017;72:225-30.

5. Garoussi MT, Mehrzad J, Nejati A. Investigation of persistent infection of bovine viral diarrhea virus (BVDV) in Holstein dairy cows. Trop Anim Health Prod. 2019;51:853-8.

6. Pinior B, Garcia S, Minviel JJ, Raboisson D. Epidemiological factors and mitigation measures influencing production losses in cattle due to bovine viral diarrhoea virus infection: A meta-analysis. Transboundary emerging diseases. 2019;66:2426-39.

7. Noaman V, Nabinejad AR. Seroprevalence and risk factors assessment of the three main infectious agents associated with abortion in dairy cattle in Isfahan province, Iran. Tropical animal health and production 2020:1-9.

8. Ghaemmaghami S, Ahmadi M, Deniko A, Mokhberosafa L, Bakhshesh M. Serological study of BVDV and BHV-1 infections in industrial dairy herds of Arak, Iran. Iranian Journal of Veterinary Science Technology. 2013;5:53-61.

9. Erfani AM, Bakhshesh M, Fallah MH, Hashemi M. Seroprevalence and risk factors associated with bovine viral diarrhea virus and bovine herpes virus-1 in Zanjan Province, Iran. Trop Anim Health Prod. 2019;51:313-9.

10. Khodakaram-Tafti A, Farjanikish G. Persistent bovine viral diarrhea virus (BVDV) infection in cattle herds. Iranian journal of veterinary research. 2017;18:154.

11. Jin R, Zhai L, Zhu Q, Feng J, Pan X. Naked-eyes detection of Largemouth bass ranavirus in clinical fish samples using gold nanoparticles as colorimetric sensor. Aquaculture 2020:735554.

12. Ahmadi S, Kamaladini H, Haddadi F, Sharifmoghadam MR. Thiol-Capped Gold Nanoparticle Biosensors for Rapid and Sensitive Visual Colorimetric Detection of Klebsiella pneumoniae. J Fluoresc. 2018;28:987-98.

13. Draz MS, Shafiee H. Applications of gold nanoparticles in virus detection. Theranostics. 2018;8:1985.

14. Naderi M, Hosseini M, Ganjali MR. Naked-eye detection of potassium ions in a novel gold nanoparticle aggregation-based aptasensor. Spectrochim Acta Part A Mol Biomol Spectrosc. 2018;195:75-83.

15. Swierczewska M, Liu G, Lee S, Chen X. High-sensitivity nanosensors for biomarker detection. Chem Soc Rev. 2012;41:2641-55.

16. Wang G, Akiyama Y, Shiraishi S, Kanayama N, Takarada T, Maeda M. Cross-linking versus non-crosslinking aggregation of gold nanoparticles induced by DNA hybridization: a comparison of the rapidity of solution color change. Bioconjug Chem. 2017;28:270-7. 
17. Conde J, de la Fuente JM, Baptista PV. RNA quantification using gold nanoprobes-application to cancer diagnostics. Journal of Nanobiotechnology. 2010;8:1-8.

18. Baptista P, Doria G, Henriques D, Pereira E, Franco R. Colorimetric detection of eukaryotic gene expression with DNA-derivatized gold nanoparticles. Journal of biotechnology. 2005;119:111-7.

19. Liu Y, Zhang L, Wei W, Zhao H, Zhou Z, Zhang Y, et al. Colorimetric detection of influenza A virus using antibody-functionalized gold nanoparticles. Analyst. 2015;140:3989-95.

20. Lee C, Gaston MA, Weiss AA, Zhang P. Colorimetric viral detection based on sialic acid stabilized goldnanoparticles. Biosensors Bioelectronics. 2013;42:236-41.

21. Sattarahmady N, Tondro G, Gholchin M, Heli H. Gold nanoparticles biosensor of Brucella spp. genomic DNA: Visual and spectrophotometric detections. Biochemical engineering journal. 2015;97:1-7.

22. Khan SA, Singh AK, Senapati D, Fan Z, Ray PC. Targeted highly sensitive detection of multi-drug resistant salmonella DT104 using gold nanoparticles. Chem Commun. 2011;47:9444-6.

23. Bakthavathsalam P, Rajendran VK, Mohammed JAB. A direct detection of Escherichia coli genomic DNA using gold nanoprobes. Journal of nanobiotechnology. 2012;10:8.

24. Kim H, Park M, Hwang J, Kim JH, Chung D-R, Lee K-s, et al. Development of label-free colorimetric assay for MERS-CoV using gold nanoparticles. ACS sensors. 2019;4:1306-12.

25. Zhao W, Brook MA, Li Y. Design of gold nanoparticle-based colorimetric biosensing assays. ChemBioChem. 2008;9:2363-71.

26. Mirkin CA, Letsinger RL, Mucic RC, Storhoff JJ. A DNA-based method for rationally assembling nanoparticles into macroscopic materials. Nature. 1996;382:607-9.

27. Ahmadpour-Yazdi H, Hormozi-Nezhad M, Abadi A, Sanati MH, Kazemi B. Colorimetric assay for exon 7 SMN1/SMN2 single nucleotide polymorphism using gold nanoprobes. Biolmpacts: BI. 2013;3:185.

28. Soo P-C, Horng Y-T, Chang K-C, Wang J-Y, Hsueh P-R, Chuang C-Y, et al. A simple gold nanoparticle probes assay for identification of Mycobacterium tuberculosis and Mycobacterium tuberculosis complex from clinical specimens. Mol Cell Probes. 2009;23:240-6.

29. Mollasalehi H, Yazdanparast R. Non-crosslinking gold nanoprobes for detection of nucleic acid sequence-based amplification products. Anal Biochem. 2012;425:91-5.

30. Esmaeili-Bandboni A, Amini SM, Faridi-Majidi R, Bagheri J, Mohammadnejad J, Sadroddiny E. Crosslinking gold nanoparticles aggregation method based on localised surface plasmon resonance for quantitative detection of miR-155. IET nanobiotechnology. 2018;12:453-8.

31. Zhang W, Guo S, Carvalho WSP, Jiang Y, Serpe MJ. Portable point-of-care diagnostic devices. Anal Methods. 2016;8:7847-67.

32. Vaseghi A, Safaie N, Bakhshinejad B, Mohsenifar A, Sadeghizadeh M. Detection of Pseudomonas syringae pathovars by thiol-linked DNA-Gold nanoparticle probes. Sens Actuators B. 2013;181:64451. 
33. Baptista P, Pereira E, Eaton P, Doria G, Miranda A, Gomes I, et al. Gold nanoparticles for the development of clinical diagnosis methods. Analytical bioanalytical chemistry. 2008;391:943-50.

34. Kimling J, Maier M, Okenve B, Kotaidis V, Ballot H, Plech A. Turkevich method for gold nanoparticle synthesis revisited. J Phys Chem B. 2006;110:15700-7.

35. Zehbe I, Hacker GW, Su H, Hauser-Kronberger C, Hainfeld JF, Tubbs R. Sensitive in situ hybridization with catalyzed reporter deposition, streptavidin-Nanogold, and silver acetate autometallography: detection of single-copy human papillomavirus. Am J Pathol. 1997;150:1553.

36. Heidari Z, Rezatofighi SE, Rastegarzadeh S. A novel unmodified gold nanoparticles-based assay for direct detection of unamplified bovine viral diarrhea virus-RNA. J Nanosci Nanotechnol. 2016;16:12344-50.

37. Askaravi M, Rezatofighi SE, Rastegarzadeh S, Shapouri MRSA. Development of a new method based on unmodified gold nanoparticles and peptide nucleic acids for detecting bovine viral diarrhea virusRNA. AMB Express. 2017;7:137.

38. Sato K, Hosokawa K, Maeda M. Rapid aggregation of gold nanoparticles induced by non-crosslinking DNA hybridization. J Am Chem Soc. 2003;125:8102-3.

39. He Z, Yang H. Colourimetric detection of swine-specific DNA for halal authentication using gold nanoparticles. Food Control. 2018;88:9-14.

40. Demers LM, Mirkin CA, Mucic RC, Reynolds RA, Letsinger RL, Elghanian R, et al. A fluorescence-based method for determining the surface coverage and hybridization efficiency of thiol-capped oligonucleotides bound to gold thin films and nanoparticles. Analytical chemistry. 2000;72:5535-41.

41. Gilbert S, Burton K, Prins S, Deregt D. Typing of bovine viral diarrhea viruses directly from blood of persistently infected cattle by multiplex PCR. J Clin Microbiol. 1999;37:2020-3.

42. Aebischer A, Wernike K, Hoffmann B, Beer M. Rapid genome detection of Schmallenberg virus and bovine viral diarrhea virus by use of isothermal amplification methods and high-speed real-time reverse transcriptase PCR. J Clin Microbiol. 2014;52:1883-92.

\section{Tables}




\begin{tabular}{|c|c|c|c|}
\hline Assay & Name & Sequence $\left(5^{\prime} \rightarrow 3^{\prime}\right)$ & Reference \\
\hline \multirow{5}{*}{$\begin{array}{l}\text { CL or NCL probe-AuNP } \\
\text { hybridization assay }\end{array}$} & Probe-A & SHA(10) GCAACCTACCGACTT & $\begin{array}{l}\text { This } \\
\text { paper }\end{array}$ \\
\hline & Probe-B & GGACTCATGTCCCAT A(10)SH & $\begin{array}{l}\text { This } \\
\text { paper }\end{array}$ \\
\hline & Target & CGTTGGATGGCTGAAGCCCTGAGTACAGGGTA & $\begin{array}{l}\text { This } \\
\text { paper }\end{array}$ \\
\hline & $\begin{array}{l}\text { Mismatch } \\
\text { target }\end{array}$ & CGATGGATCGCTGAAGCCCTGAGTACGGGCTA & $\begin{array}{l}\text { This } \\
\text { paper }\end{array}$ \\
\hline & $\begin{array}{l}\text { Deleted } \\
\text { target }\end{array}$ & CGTGATGGCTGAAGCCCTGAGTACGGTA & $\begin{array}{l}\text { This } \\
\text { paper }\end{array}$ \\
\hline \multirow{5}{*}{$\begin{array}{l}\text { RT-nested } \\
\text { multiplexPCR }\end{array}$} & ExF & AAGATCCACCCTTATGA(A/G)GC & {$[41]$} \\
\hline & ExR & AAGAAGCCATCATC(A/C)CCACA & {$[41]$} \\
\hline & InF BVDV-1 & TGGAGATCTTTCACACAATAGC & {$[41]$} \\
\hline & Inf BVDV-2 & GGGAACCTAAGAACTAAATC & {$[41]$} \\
\hline & $\ln R$ & GCTGTTTCACCCAGTT(A/G)TACAT & {$[41]$} \\
\hline \multirow[t]{3}{*}{ Real-time RT-PCR } & Pesti-3F & CCTGAGTACAGGRTAGTCGTCA & {$[42]$} \\
\hline & Pesti-4R & GGCCTCTGCAGCACCCTATCA & {$[42]$} \\
\hline & $\begin{array}{l}\text { TQ-Pesti- } \\
\text { Probe }\end{array}$ & FAM-TGCYAYGTGGACGAGGGCATGC-BHQ-1 & {$[42]$} \\
\hline
\end{tabular}

Table 1. Probes, primers, and target sequences used in CL and NCL probe-AuNP hybridization assay, RTnested multiplexPCR, and real-time RT-PCR

\section{Figures}




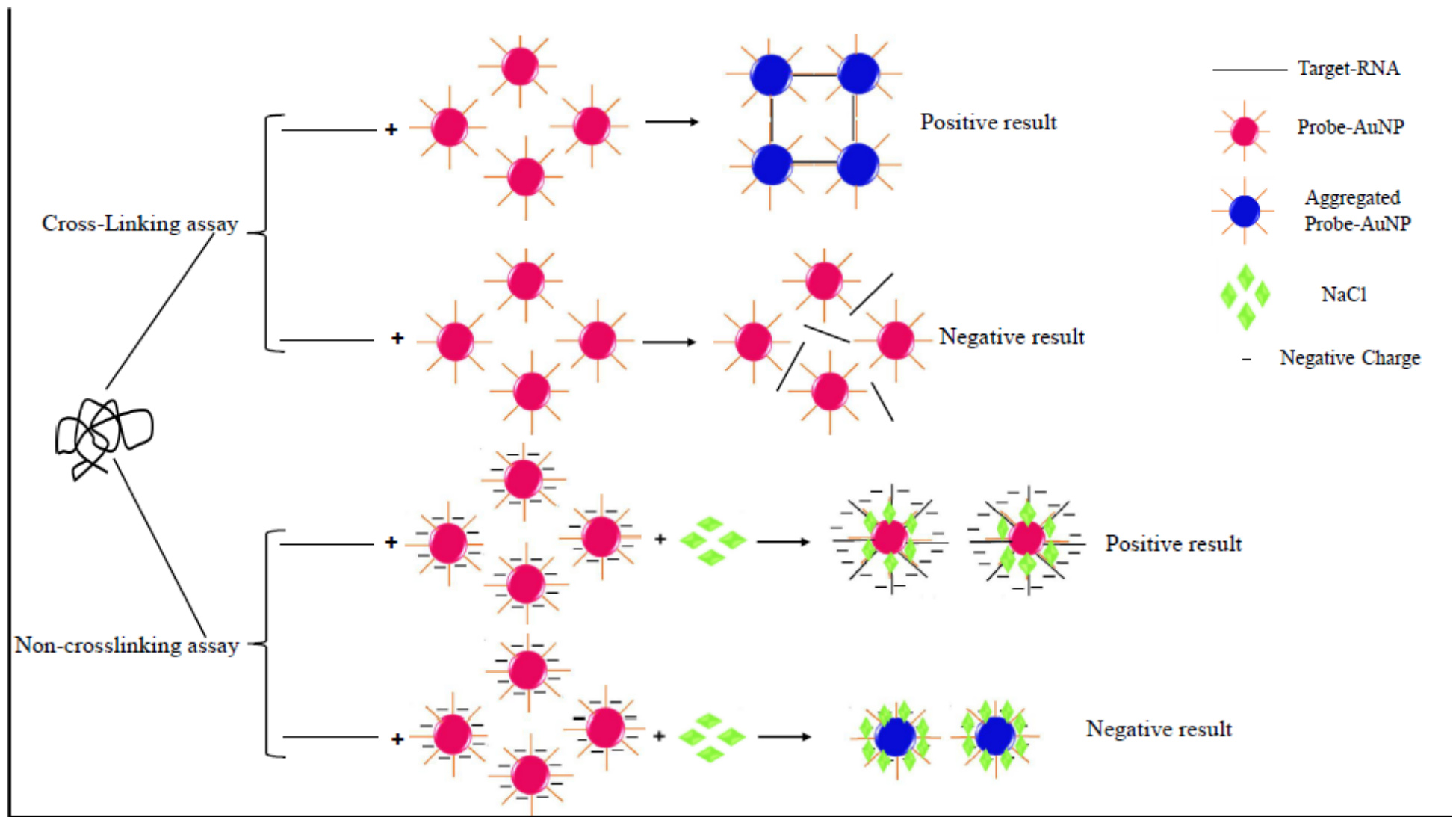

\section{Figure 1}

Schematic illustration of the colorimetric detection of nucleic acid target based on cross-linking and noncrosslinking probe-gold nanoparticle hybridization assays 


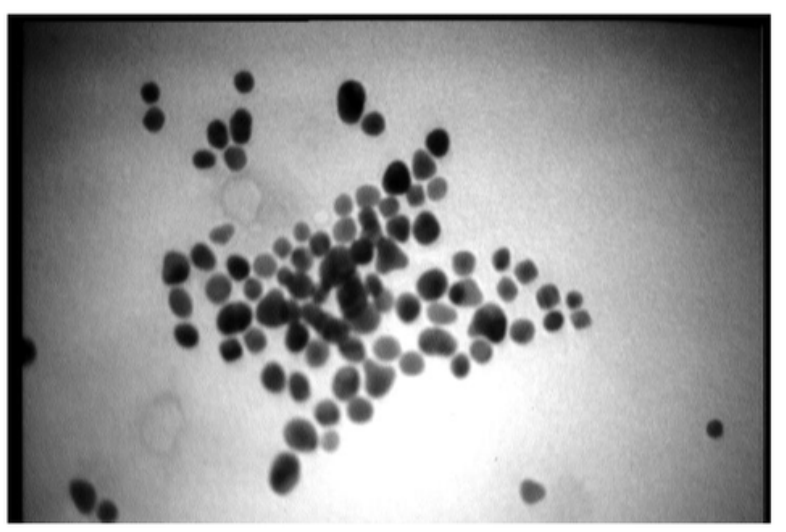

b.

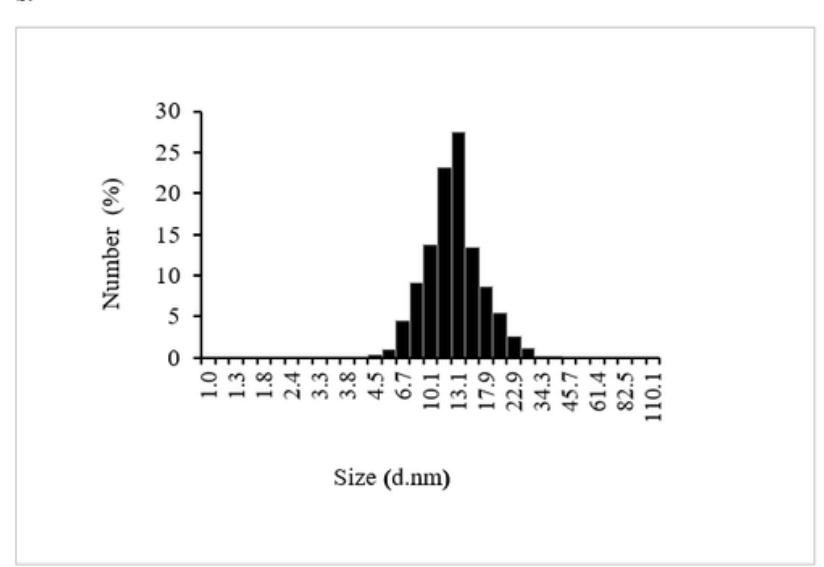

c.

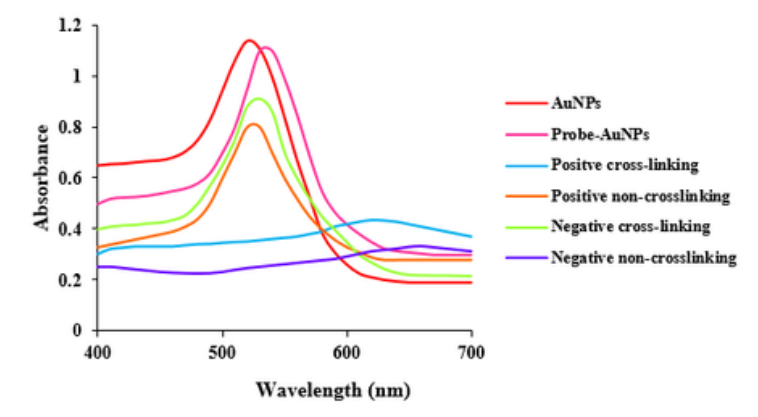

d.

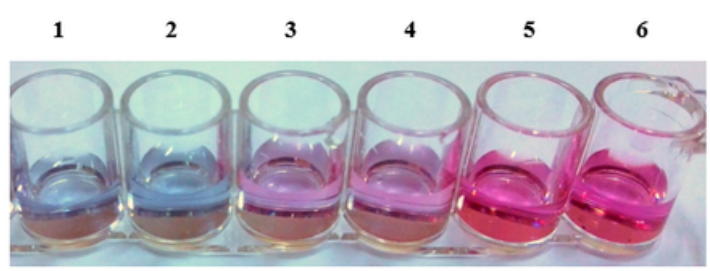

Figure 2

TEM image of AuNPs (a); AuNPs particle size distribution measured by DLS (b); UV-vis absorption spectra of the AuNPs, probe-AuNPs, positive and negative CL assays, and positive and negative NCL assays (c); Visual observation probe-AuNPs color changes in presence of positive and negative samples. From left to right, positive CL (well 1), negative NCL (well 2), negative CL (well 3), positive NCL (well 4), probe-AuNPs (well 5) and AuNPs (well 6).

a.

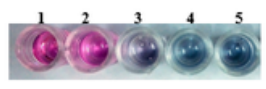

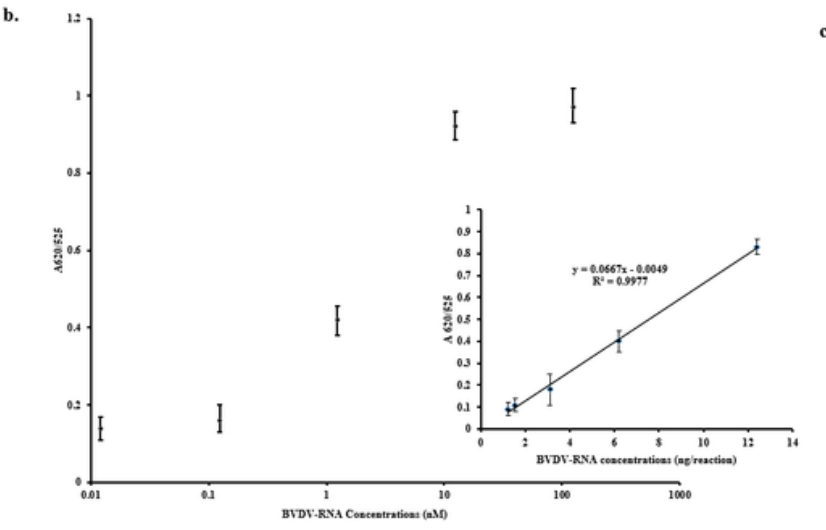

\section{Figure 3}

Visual color changes of developed CL probe-AuNPs hybridization assay at different BVDV-RNA concentrations. Wells $1-5$ contain $0.012,0.124,1.24,12.4$, and $124 \mathrm{ng} /$ reaction of RNA, respectively (a). 
Standard curve for the relationship between BVDV-RNA concentrations ( $\mathrm{ng} /$ reaction) and absorbance ratio (A620/A525) (b) and BVDV concentrations (PFU/reaction) and absorbance ratio (A620/A525) (c). Inserts are the plot of linear correlation for RNA concentrations (1.24 to $12.4 \mathrm{ng} /$ reaction) (b) and for BVDV concentrations (0.13 to $1.05 \mathrm{PFU} /$ reaction) (c).

a.

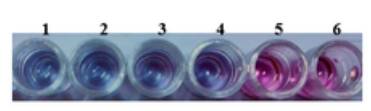

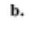

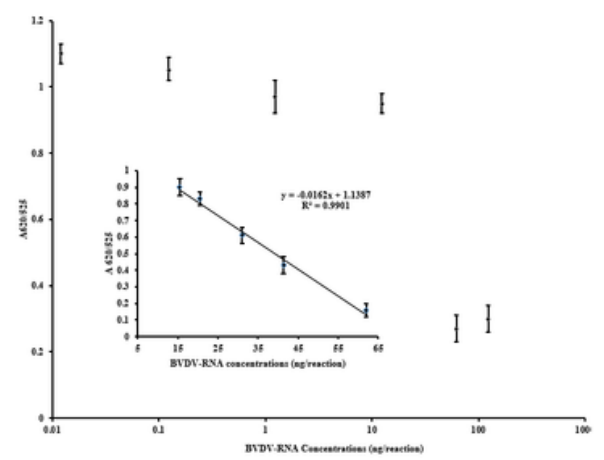

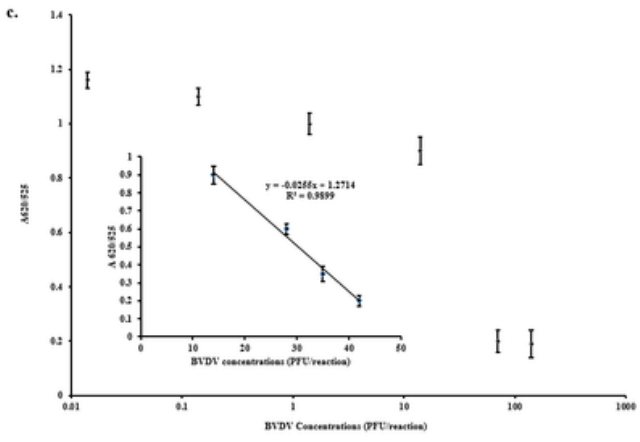

\section{Figure 4}

Visual color changes of developed NCL probe-AuNPs hybridization assay at different BVDV-RNA concentrations. Wells $1-6$ contain $0.012,0.124,1.24,12.4,62$, and $124 \mathrm{ng} /$ reaction of RNA, respectively (a). Standard curve for the relationship between BVDV-RNA concentrations ( $\mathrm{ng} /$ reaction) and absorbance ratio (A620/A525) (b) and BVDV concentrations (PFU/reaction) and absorbance ratio (A620/A525) (c). Inserts are the plot of linear correlation for RNA concentrations (15.5 to $62 \mathrm{ng} /$ reaction) (b) and for BVDV concentrations (14 to 42 PFU/reaction) (c).

\section{Supplementary Files}

This is a list of supplementary files associated with this preprint. Click to download.

- graphicabstract.docx 